
(RESURGE)

Alessandro Antonelli, Alessandro Veccia, Nicola Pavan, Carmen Mir, Alberto Breda, Toshio Takagi, Koon H. Rha, Tobias Maurer, Chao Zhang, Jean-Alexandre Long , Cosimo De Nunzio , Estevão Lima, Matteo Ferro , Salvatore Micali , Giuseppe Quarto, Estefania Linares , Antonio Celia, Luigi Schips, Pierluigi Bove, Alessandro Larcher, UROLOGY

Cristian Fiori, Alexandre Mottrie, Ahmet Bindayi,

Carlo Trombetta, Tommaso Silvestri , Joan Palou ,

Oscar Rodriguez Faba, Kazunari Tanabe, Bo Yang ,

Gaelle Fiard, Andrea Tubaro, Joao Nuno Torres ,

Ottavio De Cobelli , Luigi Bevilacqua, Roberto Castellucci ,

Andrew Tracey, Lance J. Hampton, Francesco Montorsi ,

Sisto Perdonà, Claudio Simeone, Carlotta Palumbo ,

Umberto Capitanio, Ithaar Derweesh, Francesco Porpiglia ,

Riccardo Autorino

PII:

DOI:

Reference:

To appear in:

Received date:

Accepted date:
S0090-4295(19)30264-X

https://doi.org/10.1016/j.urology.2019.03.009

URL 21511

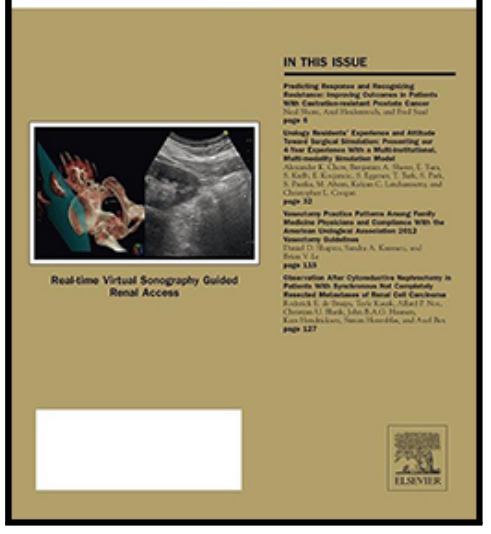

Please cite this article as: Alessandro Antonelli, Alessandro Veccia, Nicola Pavan, Carmen Mir, Alberto Breda, Toshio Takagi, Koon H. Rha , Tobias Maurer, Chao Zhang , Jean-Alexandre Long, Cosimo De Nunzio, Estevão Lima, Matteo Ferro, Salvatore Micali , Giuseppe Quarto, Estefania Linares, Antonio Celia, Luigi Schips, Pierluigi Bove , Alessandro Larcher, Cristian Fiori, Alexandre Mottrie, Ahmet Bindayi, Carlo Trombetta, Tommaso Silvestri, Joan Palou, Oscar Rodriguez Faba, Kazunari Tanabe, Bo Yang , Gaelle Fiard, Andrea Tubaro, Joao Nuno Torres, Ottavio De Cobelli, Luigi Bevilacqua , Roberto Castellucci, Andrew Tracey, Lance J. Hampton, Francesco Montorsi, Sisto Perdonà, Claudio Simeone, Carlotta Palumbo, Umberto Capitanio, Ithaar Derweesh, Francesco Porpiglia, Riccardo Autorino, OUTCOMES OF PARTIAL AND RADICAL NEPHRECTOMY IN OCTOGENARIANS - A MULTICENTER INTERNATIONAL STUDY (RESURGE), Urology (2019), doi: https://doi.org/10.1016/j.urology.2019.03.009

This is a PDF file of an unedited manuscript that has been accepted for publication. As a service to our customers we are providing this early version of the manuscript. The manuscript will undergo copyediting, typesetting, and review of the resulting proof before it is published in its final form. Please 
note that during the production process errors may be discovered which could affect the content, and all legal disclaimers that apply to the journal pertain. 


\section{OUTCOMES OF PARTIAL AND RADICAL NEPHRECTOMY IN OCTOGENARIANS - A MULTICENTER INTERNATIONAL STUDY (RESURGE)}

Alessandro Antonelli ${ }^{1}$, Alessandro Veccia ${ }^{1,2}$, Nicola Pavan ${ }^{3}$, Carmen Mir ${ }^{4}$, Alberto Breda ${ }^{5}$, Toshio Takagi ${ }^{6}$, Koon H. Rha ${ }^{7}$, Tobias Maurer ${ }^{8}$, Chao Zhang ${ }^{9}$, Jean-Alexandre Long ${ }^{10}$, Cosimo De Nunzio ${ }^{11}$, Estevão Lima ${ }^{12}$, Matteo Ferro ${ }^{13}$, Salvatore Micali ${ }^{14}$, Giuseppe Quarto ${ }^{15}$, Estefania Linares ${ }^{16}$, Antonio Celia ${ }^{17}$, Luigi Schips $^{18}$, Pierluigi Bove ${ }^{19}$, Alessandro Larcher ${ }^{20}$, Cristian Fiori ${ }^{21}$, Alexandre Mottrie ${ }^{22}$, Ahmet Bindayi ${ }^{23}$, Carlo Trombetta ${ }^{3}$, Tommaso Silvestri ${ }^{3}$, Joan Palou ${ }^{5}$, Oscar Rodriguez Faba ${ }^{5}$, Kazunari Tanabe ${ }^{6}$, Bo Yang $^{9}$, Gaelle Fiard ${ }^{10}$, Andrea Tubaro $^{11}$, Joao Nuno Torres ${ }^{12}$, Ottavio De Cobelli ${ }^{13}$, Luigi Bevilacqua ${ }^{14}$, Roberto Castellucci ${ }^{18}$, Andrew Tracey ${ }^{2}$, Lance J. Hampton ${ }^{2}$, Francesco Montorsi ${ }^{20}$,

Sisto Perdonà ${ }^{15}$, Claudio Simeone ${ }^{1}$, Carlotta Palumbo ${ }^{1}$, Umberto Capitanio ${ }^{20}$, Ithaar Derweesh ${ }^{23}$, Francesco Porpiglia ${ }^{21}$, Riccardo Autorino ${ }^{2}$

${ }^{1}$ Urology Unit, ASST Spedali Civili Hospital, Brescia, Italy, Department of Medical and Surgical Specialties, Rediological Science, and Public Health, University of Brescia, Italy; ${ }^{2}$ Division of Urology, VCU Health, Richmond, VA, USA; ${ }^{3}$ Department of Urology, Cattinara Hospital, University of Trieste, Italy; ${ }^{4}$ Department of Urology, Instituto Valenciano de Oncología Foundation, Valencia, Spain; ${ }^{5}$ Department of Urology, Fundạció Puigvert, Universitat Autònoma de Barcelona, Barcelona, Spain; ${ }^{6}$ Department of Urology, Tokyo Women's Medical University, Tokyo, Japan; ${ }^{7}$ Department of Urology, Severance Hospital, Yonsei University College of Medicine, Seoul, Korea; ${ }^{8}$ Department 
of Urology, Medical Center rechts der Isar, Technical University of Munich, Munich,

Germany; ${ }^{9}$ Department of Urology, Changhai Hospital, Shanghai, China; ${ }^{10}$ Department of Urology and Kidney Transplantation, Grenoble University Hospital, Grenoble, France;

${ }^{11}$ Department of Urology, Hospital "Sant' Andrea", Sapienza University, Rome, Italy;

${ }^{12}$ Department of Urology, Hospital de Braga, Braga, Portugal; ${ }^{13}$ Department of Urology, European Institute of Oncology, Milan, Italy; ${ }^{14}$ Department of Urology, University of Modena and Reggio Emilia, Modena, Italy; ${ }^{15}$ Uro-Gynecological Department, Fondazione "G. Pascale" IRCCS, Naples, Italy; ${ }^{16}$ Department of Urology. Hospital Universitario La Paz. Madrid. Spain; ${ }^{17}$ Department of Urology, San Bassiano Hospital, Bassano Del Grappa, Italy; ${ }^{18}$ Department of Urology, SS. Annunziata Hospital, "G.D'Annunzio" University of Chieti, Chieti, Italy; ${ }^{19}$ Department of Urology, San Carlo di Nancy, Tor Vergata University, Rome, Italy; ${ }^{20}$ Department of Urology and Division of Experimental Oncology, URI, Urological Research Institute, IRCCS San Raffaele Scientific Institute, Milan, Italy; ${ }^{21}$ Department of Urology, San Luigi Gonzaga Hospital, University of Turin, Orbassano, Turin, Italy; ${ }^{22}$ Department of Urology, OLV Ziekenhuis, Aalst, Belgium; ${ }^{23}$ Department of Urology, UCSD Health System, La Jolla, CA, USA

\section{Corresponding Author:}

Riccardo Autorino, MD, PhD

Associate Professor of Urology

Division of Urology, VCU Medical Center

PO Box 980118, Richmond, VA 23298-0118

Phone: 804-828-5320; Fax: 804-828-2157 
Email: ricautor@gmail.com

Abstract Word Count: 242

Manuscript Word Count: 2184; References: 30; Tables: 4; Electronic supplementary material: 1

Keywords: Nephrectomy - Renal cell carcinoma - Octogenarian - Elderly - Survival

Declaration of interest:

None

Support/financial disclosure:

The authors declare that they have no relevant financial interests.

\section{Acknowledgements}

None 


\section{ABSTRACT}

Objectives. To analyze the outcomes of partial nephrectomy (PN) and radical nephrectomy $(\mathrm{RN})$ in octogenarian patients.

Methods. The RESURGE (REnal SUrgery in the Eldely) multi-institutional database was queried to identify patients $\geq 80$ years old who had undergone a PN or RN for a renal tumor. Multivariable binary logistic regression estimated the association between type of surgery and occurrence of complications. Multivariable Cox regression model assessed the association between type of surgery and All-Causes Mortality.

Results. The study analyzed 585 patients (median age 83 years, IQR $81-84$ ), 364 of whom (62.2\%) underwent RN and 221 (37.8\%) PN. Patients undergoing RN were older $(p=0.0084)$, had larger tumor size $(p<0.0001)$ and higher clinical stage $(p<0.001)$. At multivariable analysis for complications, the only significant difference was found for lower risk of major postoperative complications for laparoscopic RN compared to open RN (OR: $0.42 ; p=0.04)$. The rate of significant $(>25 \%)$ decrease of eGFR in PN and RN was $18 \%$ vs $59 \%$ at 1 month, and $23 \%$ vs $65 \%$ at 6 months ( $p$ values<0.0001). After a median follow up time of 39 months, 161 patients (31\%) died, of whom $105(20 \%)$ due to renal cancer.

Conclusions. In this patient population both RN and PN carry a non-negligible risk of complications. When surgical removal is indicated, PN should be preferred, whenever technically feasible, as it can offer better preservation of renal function, without increasing the risk of complications. Moreover, a minimally invasive approach should be pursued, as it can translate into lower surgical morbidity. 
Abbreviations: PN: Partial Nephrectomy; RN: Radical Nephrectomy; RESURGE: REnal SUrgery in the Elderly; RCC: Renal Cell Carcinoma; AS: Active Surveillance; ACM: All-Causes Mortality; eGFR: estimated Glomerular Filtration Rate

\section{Introduction}

Renal Cell Carcinoma (RCC) has a peak in its incidence between the sixth and seventh decade, but older patients cover up to a third of new diagnoses ${ }^{1}$, and their number is on the rise given prolonged life expectancy. Thus, urologists, oncologists and geriatricians will be increasingly facing with the complex issue of how to manage RCC in the "very" elderly. Especially in this setting, patients' and tumor's features needs to be considered to assess which management option offers the optimal trade-off between risks and benefits.

Despite general trend is in favour of partial nephrectomy $(\mathrm{PN})$ and minimally invasive approaches ${ }^{2}$, in many centers open radical nephrectomy (ORN) still represents the preferred surgical way in very elderly subjects ${ }^{3}$. Evidence supporting nephronsparing and minimally invasive approaches for these subjects remains sparse, and studies adopted liberal definitions of "elderly" (as over 65,70 or 75 years $\left.{ }^{4,5}\right)^{6}$. Only a handful number of small series focused their attention "octogenarians" or "oldest old", as defined by the World Health Organization ${ }^{7}$.

The aim of this study was to provide a comprehensive comparison of surgical, functional and survival outcomes of PN versus RN in these "very elderly" (octogenarian) patients through the analysis of a multi-institutional international dataset (RESURGE: REnal SURGery in the Elderly). 


\section{Material and methods}

\section{Study design}

The RESURGE project involves 23 Institutions from Europe, United States and Asia, with the objective to collect a large dataset on elderly patients undergoing surgery for RCC between 2000 and 2016. A data-sheet was shared and merged, reporting pre-, intra- and post-operative data, functional and survival follow up information 8,9 . Institutional Review Board approval was obtained by each center.

The present study retrospectively analyzes the patients aged 80 years-old or more with complete data. Comorbidities were described by the Charlson-Romano score $^{10}$; Glomerular Filtration Rate was estimated (eGFR) by the chronic kidney disease epidemiology collaboration (CKD-EPI) formula11; the staging system was updated to the 2017 edition of the TNM classification ${ }^{12}$; post-operative complications were classified in agreement with the Clavien-Dindo system ${ }^{13}$. The indication to surgery, as well as the type of surgery (PN or RN) and approach were established at each Institution following surgeon's and patient's preferences. Follow up was conducted according to various schedules at each Institution and incomplete data were retrieved by registries consultation or phone interview. The causes of death were detailed as due to RCC or other reasons.

\section{Statistical analysis}

Categorical variables were described as numbers and proportions; continuous variables as medians and interquartile range (IQR). Patients submitted to $P N$ vs $R N$ 
were compared by the Pearson's chi-square test and Kruskal-Wallis $\mathrm{h}$ test for categorical and continuous variables, respectively.

Multivariable binary logistic regression estimated the association between the type of surgery (PN or RN) and the occurrence of intra-, overall post-operative and major post-operative complications. Potential confounders (age, gender, BMI, Charlson score - 0 vs $1-2$ vs $\geq 3$, open vs laparoscopic vs robotic approaches, pathological tumor size, R.E.N.A.L. score, $p T$ - $p T 1$ vs $p T 2$ vs $p T>2, p N$ - pN0 vs pNx vs $p N+$, low vs high grading) were initially tested at univariate analysis and only those with a $p$ significance $<0.1$ were included into final multivariable analysis.

Following a similar design, multivariable Cox regression model assessed the association between the type of surgery and All-Causes Mortality (ACM), imputing time intervals as the period in months between surgery and death due to RCC or other causes or the last available control. All statistical analysis was performed with STATA®15 (StataCorp LLC, College Station, TX, USA).

\section{Results}

The study analyzed the data of 585 "octogenarian" patients (median age 83 years, IQR 81-84), 364 of whom (62.2\%) underwent RN and 221 (37.8\%) PN. Patients undergoing RN were older (83.1 vs 82.4 years, $\mathrm{p}=0.0084$ ), had lower prevalence of hypertension ( $58 \%$ vs $70 \%, p=0.005)$, higher rate of baseline CKD stage III ( $47 \%$ vs $30 \%, p=0.038$ ), larger clinical size ( 5.9 vs $3.5 \mathrm{~cm}, \mathrm{p}<0.0001$ ), higher clinical stage $(p<0.001)$. Baseline eGFR and distribution of Charlson scores were similar between 
groups. Moreover, pathological tumor size, pathological staging and grading were more advanced in the RN group (Table 1).

\section{Peri-operative morbidity}

PN had shorter operative time (150 [IQR 118-200] vs 170 [125-220] mins; $\mathrm{p}=0.020)$ and similar EBL (200 [100-400] vs 225 [100-400] ml; $\mathrm{p}=0.1573)$, whereas no difference was recorded for complications between the two study groups (Table 2).

At multivariable analysis for complications, the only significant difference was found for lower risk of major postoperative complications for laparoscopic RN compared to open RN (OR: 0.42; $p=0.04$ ) (Table 3). A detailed description of complications is summarized in electronic supplementary table $\mathbf{1}$,

\section{Functional outcomes}

Starting from similar baseline eGFR (RN median eGFR $60 \mathrm{ml} / \mathrm{min}$, IQR 45-73; PN $60 \mathrm{ml} / \mathrm{min}$, IQR 46-77, $\mathrm{p}=0.3588$ ), the observed variations in eGFR after $\mathrm{PN}$ and $\mathrm{RN}$ were $-3(\mathrm{IQR}-13,0)$ vs $-16(\mathrm{IQR}-26,-8) \mathrm{ml} / \mathrm{min}$ and $-6(-14,0)$ vs $-17(-27,-8) \mathrm{ml} / \mathrm{min}$, at 1 and 6 months respectively. The respective percentage variations were $-3 \%$ (IQR $13 \%, 0 \%)$ vs $-35 \%$ (IQR $-42 \%,-13 \%$ ) and $-6 \%$ (IQR $-14 \%, 0 \%$ ) vs $-31 \%$ (IQR $-42 \%$, $15 \%$ ) (all $p$ values $<0.0001)$. The rate of significant $(>25 \%$ ) decrease of eGFR in PN and RN was $18 \%$ vs $59 \%$ at 1 month, and $23 \%$ vs $65 \%$ at 6 months (all p values $<0.0001$ ). Survival Analysis

After a median follow up time of 39 months (IQR 12-54), 161 patients (31\%) died, $105(20 \%)$ due to renal cancer and $59(11 \%)$ for other causes. At univariate analysis ACM was associated to a Charlson index $\geq 3$ (HR 1.6, $p=0.017)$, type of surgery (RN referent, HR for PN 0.7, $p=0.033$ ) and a pT stage $\geq 3$ (pT1-2 referent, $H R$ for $p T \geq 31.5$, 
$p=0.066)$. However, none of these factors reached statistical significance at multivariable analysis (Table 4).

\section{Discussion}

Current guidelines recommend PN over RN in resectable cT1 RCC, as better preservation of renal function protects from cardiovascular events ${ }^{14}$, and, according to more recent evidence, might even decrease cancer-specific mortality ${ }^{15}$. While the debate on which patients are really harmed by $\mathrm{RN}$ is ongoing ${ }^{16}$, several studies suggest that PN might be especially advantageous in more comorbid and frailer subjects ${ }^{17}$. However, in clinical practice RN seems to be still preferred to PN in the oldest patients. Population studies on large US datasets indeed show that PN for T1a RCC is done in $68 \%$ of $20-44$ years subjects ${ }^{18}$, but only $28 \%$ in those over 65 years old ${ }^{19}$. These figures suggest that PN is generally disregarded in elderly patients likely because they are considered at higher risk for surgery-related complications. This translates into neglecting the potential advantagges related to a better preservation of an already compromised baseline renal function.

The present study gives an insight in a large, multi-institutional cohort of "oldest old" (octogenarian) patients, a population representing probably the contemporary frontier for surgery, being close to the limit of life expectancy in industrialized countries ${ }^{7}$. The analysis of this unique dataset allowed to have some interesting findings.

First, $\mathrm{PN}$ or RN were both adopted as surgical approach at the participating Institutions, and minimally invasive approach was preferred in about $40 \%$ of cases. Not surprisingly, $\mathrm{RN}$ was preferred for larger (mean tumor size $5.9 \mathrm{~cm})$ and higher stage $(70 \%$ clinical 
stage T2-4) tumors, whereas PN was mostly adopted for the so called small renal mass (SRM) (mean tumor size $3.5 \mathrm{~cm}$ and about $80 \%$ cT1 stage). Second, both RN and PN carry a non-negligible number of overall and major complications in this patient population. In this respect, our data are consistent with those of literature $20,21,22$ Nevertheless, our analysis also suggests that, despite being a potential more harmful procedure, PN might not carry a higher risk of complications over $\mathrm{RN}$, and therefore it should not be discouraged solely based on the elderly age. Third, it is confirmed that PN offered a significant higher preservation of renal function keeping these subjects with borderline or impaired baseline function within safety limits with respect to end-stage CKD. Last, we found that despite advanced age, RCC represents a primary cause of death, confirming that elderly patients are often burdened by more aggressive and lethal tumors, as previously reported ${ }^{23}$. ACM was not influenced by the type of surgery but comorbidities and tumor stage, confirming that $\mathrm{PN}$ provide equivalent survival as $\mathrm{RN}$, but also indicating that within this age group no survival advantages should be $\operatorname{expected}^{22}$

The available literature on kidney cancer surgery in octogenarian patients remains sparse, with only a handful number of studies specifically focusing on the "oldest old" (Electronic supplementary table 2). Hellenthal et al showed in a large cohort of patients extracted from Surveillance, Epidemiology, and End Results database that PN was less used for elderly patients and cancer mortality similar in two matched groups of $\leq 80$ vs $\geq 80$ years old. The latter group had however higher other causes mortality and was 1.31 folds likely to die for any causes and 2.54 times for RCC when submitted to $\mathrm{RN}^{6}$. More recently, May et al performed a multicenter analysis comparing 
mortality of octogenarians with younger patients showing that cancer-specific mortality was related to age and tumor's features and not to the type of surgery ${ }^{25}$. Tang et al retrospectively analyzed a group of 115 patients with a median age of 82 by comparing active surveillance (AS), PN and RN. No difference in overall survival or diseasespecific survival among the three management strategies was found on univariable analysis, and multivariable analysis for overall survival found the Charlson comorbidity index as the only factor associated with worse survival. Therefore, the authors concluded that an "active treatment" (either PN or RN) might not provide a survival advantage compared with AS in this group of patients ${ }^{26}$. The feasibility of laparoscopic approaches with acceptable complications rates in these patients was first showed by the studies of Pareek et $\mathrm{al}^{20}$ and Thomas et $\mathrm{al}^{21}$. On the other hand, a multicenter analysis from 5 academic centers in France on 180 octogenarians mostly submitted to open $\mathrm{RN}\left(80 \%\right.$ of sample) found that morbidity and mortality were significant ${ }^{27}$. In this respect, our analysis shows that a minimally invasive approach for $\mathrm{RN}$ should be preferred, as it offer a lower risk ( $\mathrm{OR}=0.42)$ of major complications, which especially in this group of patients might have a clinically significant impact.

The present study presents the largest cohort of octogenarians to date reported, and it offers a comprehensive analysis of surgical outcomes. We confirmed that PN and minimally invasive approaches are feasible with lower complications. This is a noteworthy advantage in this subset of patients burdened by risks specifically related to the hospitalization, as falls and fractures, delirium, etc. Moreover, this is the first study investigating changes in renal function in the oldest old showing that PN could avoid or delay end-stage CKD with its detrimental effects in such population ${ }^{5}$. Finally, we 
confirmed that patient's comorbidity status and tumor's features rather that type of surgery have an impact on survival, probably because the functional advantages that are attributable to PN end up being diluted in subjects with shorter life expectancy. Nevertheless, octogenarian are patients to whom the best choice treatment still remains a dilemma. General conditions, changed physiology, life expectancy, medications, and patients' expectations make elderly suitable for other kind of treatments. In a significant portion of the aforementioned population, Active Surveillance (AS) represents a valid alternative treatment which is gaining more relevance. Literature evidences demonstrated that on careful selected patients AS gives valuable results. Indeed, in a review on 17 studies including 36496 elderly, it was shown that AS presents a low rate of conversion to active treatment with mortality related more to comorbidities rather than $\mathrm{RCC}^{27}$. Likewise, less invasive treatment as SRM ablation could be considered as an alternative in octogenarian. Among the few studies available, this procedure demonstrated to be safe and feasible without compromising survival outcomes. Moreover, the analysis of post-operative and functional outcomes revealed optimal results making percutaneous ablation an attractive form of treatment ${ }^{28}$.

Our study is not devoid of limitations. The retrospective design carries inherent biases related to data collection and selection bias for the type of surgery. Such a bias has been widely debated into the literature, and only a randomized trial could account for it. Moreover, the fact that participating Institutions are academic and/or referral centers, which limits the reproducibility of these findings in other types of hospital settings. In addition, given the multicenter nature of the study, there is an intrinsic heterogeneity in surgical technique and expertise among the different institutions (and 
surgeons) that is difficult to account for, and this should be taken into account when interpreting our study findings. The lack of control groups for AS and tumor ablation can be also regarded as an additional limitation, as these are two safe and effective management options in this patients population ${ }^{27,28}$. Moreover, the median study followup is was just over 3 years, which in general might not be considered fully adequate when studying a population with kidney cancer. However, given the advanced age of these patients (and related limited life expectancy), we believe it is still meaningful to look at this time frame. Last, the lack of validated tools to assess frailty that should become mandatory in future studies in this subset of patients ${ }^{29}$.

\section{Conclusions}

The management of renal mass in the octogenarian patient represents a challenging scenario. This multicenter analysis, based on "real life" data, allows to get some useful information that can be used for patient counseling and surgical decision-making. One should be aware that in this patient population both $\mathrm{RN}$ and $\mathrm{PN}$ can carry a non-negligible risk of complications, and therefore they should be reserved for larger tumors where more conservative approaches (AS; ablation) are suboptimal. When surgical removal is indicated, PN should be preferred over RN, whenever technically feasible, as it can offer better preservation of renal function, without increasing the risk of complications. Moreover, a minimally invasive approach should be pursued in this very frail population, as it can potentially translate into lower surgical morbidity. 


\section{References}

1. Capitanio U, Bensalah K, Bex A, et al. Epidemiology of Renal Cell Carcinoma. Eur Urol. 2018. doi:10.1016/j.eururo.2018.08.036.

2. Schiavina R, Mari A, Antonelli A et al. A snapshot of nephron-sparing surgery in Italy: a prospective, multicenter report on clinical and perioperative outcomes (the RECORd 1 project). Eur J Surg Oncol. 2015;41:346-352. doi: 10.1016/j.ejso.2014.12.001.

3. Bianchi M, Becker A, Abdollah F, et al. Rates of open versus laparoscopic and partial versus radical nephrectomy for T1a renal cell carcinoma: a populationbased evaluation. Int J Urol. 2013;20:1064-1071. doi: 10.1111/iju.12110.

4. White VM, Marco DJT, Bolton D, et al. Age at diagnosis and the surgical management of small renal carcinomas: findings from a cross-sectional population-based study. BJU Int 2018. doi:10.1111/bju.14585.

5. An JY, Ball MW, Gorin MA, et al. Partial vs Radical Nephrectomy for T1-T2 Renal Masses in the Elderly: Comparison of Complications, Renal Function, and Oncologic Outcomes. Urology. 2017;100:151-157. doi: 10.1016/j.urology.2016.10.047.

6. Hellenthal NJ, Mansour AM, Hayn MH, Schwaab T. Renal Cell Carcinoma in Octogenarians: Nephron Sparing Surgery Should Remain the Standard of Care. J Urol. 2011;185:415-420. doi: 10.1016/j.juro.2010.09.071.

7. Health in older age. In: World report on ageing and health. World Health Organization. Geneva, Switzerland: (c) World Health Organization 2015:43-88. 
8. Larcher A, Capitanio U, Antonelli A, et al. Minimally invasive partial nephrectomy for elderly patients with renal mass: Morbidity, renal function and oncologic outcomes in the RESURGE collaborative database. EUR Urol Suppl. 2018: 17: e291-e292. doi: 10.1016/S1569-9056(18)31054-6

9. Pavan N, Silvestri T, Antonelli A, et al. Surgical outcomes and predictors of complications in elderly patients undergoing partial or radical nephrectomy for clinically localized renal cancer: A multi-institutional analysis (RESURGE project). EUR Urol Suppl. 2018; 17; e1476-e1477. doi: 10.1016/S15699056(18)31867-0

10. Charlson ME, Pompei P, Ales KL, MacKenzie CR. A new method of classifying prognostic comorbidity in longitudinal studies: development and validation. $J$ Chronic Dis. 1987; 40:373-383.

11. Levey AS, Stevens LA. Estimating GFR using the CKD Epidemiology Collaboration (CKD-EPI) creatinine equation: more accurate GFR estimates, lower CKD prevalence estimates, and better risk predictions. Am J Kidney Dis. 2010; 55:622-627. doi: 10.1053/j.ajkd.2010.02.337.

12. Paner GP, Stadler WM, Hansel DE, Montironi R, Lin DW, Amin MB. Updates in the Eighth Edition of the Tumor-Node-Metastasis Staging Classification for Urologic Cancers. Eur Urol. 2018; 73:560-569. doi: 10.1016/j.eururo.2017.12.018.

13.Dindo D, Demartines N, Clavien P-A. Classification of surgical complications: a new proposal with evaluation in a cohort of 6336 patients and results of a survey. Ann Surg. 2004; 240:205-213. 
14. Huang WC, Elkin EB, Levey AS, Jang TL, Russo P. Partial nephrectomy versus radical nephrectomy in patients with small renal tumors--is there a difference in mortality and cardiovascular outcomes? J Urol. 2009; 181:55-61. doi: 10.1016/j.juro.2008.09.017.

15. Bandini M, Marchioni M, Pompe RS, et al. The effect of age on cancer specific mortality in patients with small renal masses: A population-based analysis. Can Urol Assoc J. 2018; doi:10.5489/cuaj.4854.

16. Scosyrev E, Messing EM, Sylvester R, Van Poppel H. Exploratory Subgroup Analyses of Renal Function and Overall Survival in European Organization for Research and Treatment of Cancer randomized trial of Nephron-sparing Surgery Versus Radical Nephrectomy. Eur Urol Focus. 2017; 3:599-605. doi: 10.1016/j.euf.2017.02.015.

17. Capitanio U, Larcher A, Terrone C, et al. End-Stage Renal Disease After Renal Surgery in Patients with Normal Preoperative Kidney Function: Balancing Surgical Strategy and Individual Disorders at Baseline. Eur Urol. 2016; 70:558561. doi: 10.1016/j.eururo.2016.03.023.

18. Wang DC, Plante K, Stewart T, et al. Comparison of survival for partial vs. radical nephrectomy in young patients with T1a renal cell carcinoma treated at commission on cancer-accredited facilities and influence of comorbidities on treatment choice. Urol Oncol. 2017; 35: 660.e9-660.e15. doi: 10.1016/j.urolonc.2017.06.056.

19. Patel HD, Kates M, Pierorazio PM, Allaf ME. Race and sex disparities in the treatment of older patients with T1a renal cell carcinoma: a comorbidity- 
controlled competing-risks model. Urol Oncol. 2014; 32:576-583. doi: 10.1016/j.urolonc.2014.01.002.

20. Pareek G, Yates J, Hedican S, Moon T, Nakada S. Laparoscopic renal surgery in the octogenarian. BJU Int. 2008; 101:867-870. doi: 10.1111/j.1464410X.2007.07368.x.

21. Thomas AA, Aron M, Hernandez AV, Lane BR, Gill IS. Laparoscopic partial nephrectomy in octogenarians. Urology. 2009; 74:1042-1046. doi: 10.1016/j.urology.2009.04.099.

22. Berger J, Fardoun T, Brassart E, et al. Detailed analysis of morbidity following nephrectomy for renal cell carcinoma in octogenarians. J Urol. 2012; 188:736740. doi: 10.1016/j.juro.2012.05.008.

23. Antonelli A, Mari A, Longo N, et al. Role of Clinical and Surgical Factors for the Prediction of Immediate, Early and Late Functional Results, and its Relationship with Cardiovascular Outcome after Partial Nephrectomy: Results from the Prospective Multicenter RECORd 1 Project. J Urol. 2018; 199:927-932. doi: 10.1016/j.juro.2017.11.065.

24. Verhoest G, Veillard D, Guillé F, et al. Relationship between Age at Diagnosis and Clinicopathologic Features of Renal Cell Carcinoma. Eur Urol. 2007; 51:1298-1304. doi: 10.1016/j.eururo.2006.11.056

25. May M, Cindolo L, Zigeuner R, et al. Results of a comparative study analyzing octogenarians with renal cell carcinoma in a competing risk analysis with patients in the seventh decade of life. Urol Oncol. 2014 32:1252-1258. doi: 10.1016/j.urolonc.2014.04.013. 
26. Tang DH, Nawlo J, Chipollini J, et al. Management of Renal Masses in an Octogenarian Cohort: Is There a Right Approach? Clin Genitourin Cancer. 2017; 15:696-703. doi: 10.1016/j.clgc.2017.05.011.

27. Cheung DC, Finelli A. Active Surveillance in Small Renal Masses in the Elderly: A Literature Review. Eur Urol Focus. 2017; 3:340-351. doi: 10.1016/j.euf.2017.11.005.

28. Miller AJ, Kurup AN, Schmit GD, et al. Percutaneous Clinical T1a Renal Mass Ablation in the Octogenarian and Nonagenarian: Oncologic Outcomes and Morbidity. J Endourol. 2015; 29:671-676. doi: 10.1089/end.2014.0733.

29. Cui HW, Turney BW, Griffiths J. The Preoperative Assessment and Optimization of patients Undergoing Major Urological Surgery. Curr Urol Rep. 2017; 18:54. doi: 10.1007/s11934-017-0701-z.

30. Brunckhorst O, Volpe A, van der Poel H, et al. Training, Simulation, the Learning Curve, and How to Reduce Complications in Urology. Eur Urol Focus. 2016; 2:10-18. doi: 10.1016/j.euf.2016.02.004.

\begin{tabular}{|c|c|c|c|}
\hline 1 & $R N(364)$ a & PN (221) a & $p$ value \\
\hline \multicolumn{4}{|c|}{ Patients' baseline features } \\
\hline Age (years) & $83.1 \pm 2.7$ & $82.3 \pm 2.0$ & 0.008 \\
\hline Female gender & $181(49.7)$ & $122(55.2)$ & 0.199 \\
\hline $\mathrm{BMI}\left(\mathrm{kg} / \mathrm{m}^{2}\right)$ & $25.4 \pm 3.8$ & $25.7 \pm 3.6$ & 0.145 \\
\hline Diabetes & $82(23.1)$ & $41(20.1)$ & 0.410 \\
\hline
\end{tabular}




\begin{tabular}{|c|c|c|c|}
\hline Hypertension & $206(58.2)$ & $142(70.3)$ & 0.005 \\
\hline Preoperative Hb (mg/dL) & $12.3 \pm 2$ & $12.8 \pm 1.9$ & 0.006 \\
\hline Preoperative eGFR (mL/min) & $58.7 \pm 19.7$ & $60.4 \pm 20.3$ & 0.358 \\
\hline CKD Stage III & $55(47)$ & $17(30.4)$ & 0.038 \\
\hline $\begin{array}{c}\text { Charlson group categories } \\
0 \\
1-2 \\
\geq 3\end{array}$ & $\begin{array}{c}51(19.6) \\
91(35 \%) \\
118(45.4)\end{array}$ & $\begin{array}{l}33(18.5) \\
70(39.3) \\
75(42.2)\end{array}$ & \\
\hline \multicolumn{4}{|l|}{ Preoperative tumor's features } \\
\hline $\begin{array}{c}\text { R.E.N.A.L. Score (Complexity) } \\
4-6 \text { (Low) } \\
7-10 \text { (Intermediate) } \\
>10 \text { (high) }\end{array}$ & $\begin{array}{c}33(17.7) \\
120(64.5) \\
33(17.8)\end{array}$ & $\begin{array}{c}69(48.6) \\
69(48.6) \\
4(2.8)\end{array}$ & $<0.001$ \\
\hline Clinical dimension (cm) & $5.9 \pm 2.7$ & $3.6 \pm 1.4$ & $<0.001$ \\
\hline $\begin{array}{c}\text { cT stage } \\
1 \\
2 \\
3 \\
4\end{array}$ & $\begin{array}{c}108(29.7) \\
163(44.8) \\
75(20.6) \\
18(4,9)\end{array}$ & $\begin{aligned} 171(77.4) \\
44(19.9) \\
5(2.3) \\
1(0.4)\end{aligned}$ & $<0.001$ \\
\hline $\begin{array}{c}\text { cN stage } \\
0 \\
1 \\
2\end{array}$ & $\begin{aligned} 280 & (90.6) \\
26 & (8.4) \\
3 & (1)\end{aligned}$ & $\begin{array}{c}186(97.4) \\
4(2.1) \\
1(0.5)\end{array}$ & 0.013 \\
\hline \multicolumn{4}{|c|}{ 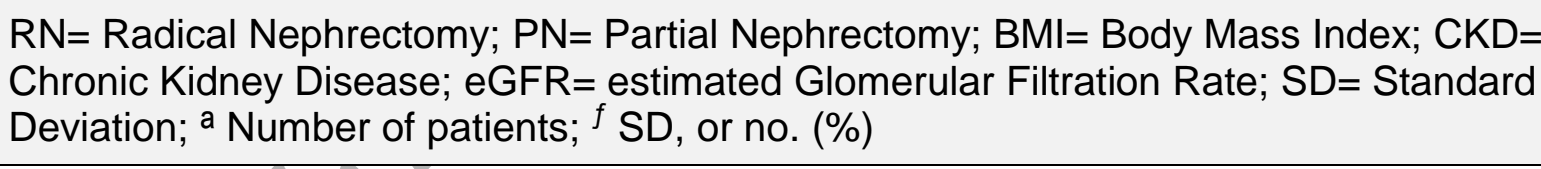 } \\
\hline
\end{tabular}

Table 1- Baseline comparison between patients who underwent radical nephrectomy (RN) and partial nephrectomy (PN) 


\begin{tabular}{|c|c|c|c|c|}
\hline & $\begin{array}{c}\text { Total } \\
(n=585)\end{array}$ & $\begin{array}{c}\text { RN } \\
(\mathrm{n}=364)\end{array}$ & $\begin{array}{c}\mathrm{PN} \\
(\mathrm{n}=221)\end{array}$ & $p$ value \\
\hline \multicolumn{5}{|l|}{ Surgical outcomes ${ }^{f}$} \\
\hline \multicolumn{4}{|l|}{ Surgical technique } & $<0.001$ \\
\hline $\begin{array}{r}\text { Open } \\
\text { Laparoscopic } \\
\text { Robotic } \\
\text { Missing }\end{array}$ & $\begin{array}{c}336(57.5) \\
177(30.2) \\
67(11.4) \\
5(0.9)\end{array}$ & $\begin{array}{c}223(61.3) \\
135(37.1) \\
4(1.1) \\
2(0.5)\end{array}$ & $\begin{array}{c}113(51.1) \\
42(19.0) \\
63(28.5) \\
3(1.4)\end{array}$ & \\
\hline Operative time (min) & - & $178.8 \pm 75.8$ & $162.6 \pm 66.9$ & 0.020 \\
\hline EBL $(m L)$ & - & $352.3 \pm 296.7$ & $300.2 \pm 337.7$ & 0.158 \\
\hline Intraoperative complications & $61(10.4)$ & $42(11.5)$ & $19(8.6)$ & 0.259 \\
\hline Post-operative complications & $146(25.0)$ & $89(24.5)$ & $57(25.8)$ & 0.716 \\
\hline Major complications & $32(5.5)$ & $21(5.8)$ & $11(5.1)$ & 0.690 \\
\hline $\begin{array}{r}\text { Open } \\
\text { Laparoscopic } \\
\text { Robotic }\end{array}$ & $\begin{array}{l}25(4.3) \\
5(0.9) \\
2(0.3)\end{array}$ & $\begin{array}{l}18(8.0) \\
3(2.2) \\
0(0.0)\end{array}$ & $\begin{array}{l}7(6.2) \\
2(4.8) \\
2(3.2)\end{array}$ & \\
\hline \multicolumn{5}{|l|}{ Pathological outcomes ${ }^{f}$} \\
\hline \multicolumn{4}{|l|}{ Tumor histology } & $<0.001$ \\
\hline $\begin{array}{r}\text { Benígn } \\
\text { Malignant } \\
\text { Missing }\end{array}$ & $\begin{array}{c}42(7.2) \\
527(90.1) \\
16(2.7)\end{array}$ & $\begin{array}{c}13(3.6) \\
348(95.6) \\
3(0.8)\end{array}$ & $\begin{array}{c}29(13.1) \\
179(81.0) \\
13(5.9)\end{array}$ & \\
\hline \multicolumn{4}{|l|}{ pT stage } & $<0.001$ \\
\hline $\begin{array}{r}1 \\
2 \\
\geq 3 \\
\text { Missing }\end{array}$ & $\begin{array}{c}368(62.9) \\
54(9.2) \\
88(15.0) \\
75(12.8)\end{array}$ & $\begin{array}{c}221(60.7) \\
49(13.5) \\
78(21.4) \\
16(4.4)\end{array}$ & $\begin{array}{c}147(66.5) \\
5(2.3) \\
10(4.5) \\
59(26.7)\end{array}$ & \\
\hline \multicolumn{4}{|l|}{ Grading } & 0.003 \\
\hline $\begin{array}{r}1-2 \\
3-4 \\
\text { Missing }\end{array}$ & $\begin{array}{c}307(52.5) \\
205(35.0) \\
73(12.5)\end{array}$ & $\begin{array}{c}185(50.8) \\
149(40.9) \\
30(8.3)\end{array}$ & $\begin{array}{l}123(55.6) \\
56(25.3) \\
42(19.0)\end{array}$ & \\
\hline \multicolumn{5}{|l|}{ Functional outcomes ${ }^{f}$} \\
\hline Pre-operative eGFR & - & $58.7 \pm 19.7$ & $60.4 \pm 20.3$ & $<0.001$ \\
\hline Post-operative eGFR at $6^{\text {th }}$ & - & $39.6 \pm 12.8$ & $51.6 \pm 19.2$ & $<0.001$ \\
\hline
\end{tabular}




\begin{tabular}{r|c|r|r|r} 
months & & & & \\
\hline eGFR variation & - & $-17.0 \pm 13.9$ & $-7.6 \pm 11.0$ & $<0.001$ \\
\hline
\end{tabular}

$\mathrm{RN}=$ Radical Nephrectomy; $\mathrm{PN}=$ Partial Nephrectomy; EBL= Estimated Blood Loss; eGFR = estimated Glomerular Filtration Rate; SD = Standard Deviation; ${ }^{f} \mathrm{SD}$, or no (\%)

Table 2. Surgical outcomes

\begin{tabular}{|c|c|c|c|c|c|c|}
\hline \multicolumn{7}{|c|}{ INTRAOPERATIVE COMPLICATION } \\
\hline & \multicolumn{3}{|c|}{ Univariate analysis } & \multicolumn{3}{|c|}{ Multivariate analysis } \\
\hline & OR & $95 \% \mathrm{Cl}$ & $p$ value & OR & $95 \% \mathrm{Cl}$ & $p$ value \\
\hline \multicolumn{7}{|l|}{ Type of surgery $^{\dagger}$} \\
\hline $\mathrm{RN}$ & Referent & & & & $1 /$ & \\
\hline PN & 0.72 & $0.40-1.27$ & 0.261 & 0.67 & $0.29-1.54$ & 0.357 \\
\hline \multicolumn{7}{|l|}{ Technique $^{\ddagger}$} \\
\hline Open & Referent & & & & & \\
\hline Laparoscopic & 0.51 & $0.26-0.97$ & 0.043 & 0.50 & 0.23-1.09 & 0.085 \\
\hline Robotic & 0.20 & $0.04-0.85$ & 0.03 & 0.28 & $0.06-1.31$ & 0.107 \\
\hline \multicolumn{7}{|l|}{ Tumor features } \\
\hline Clinical size & 1.01 & $1.00-1.02$ & 0.008 & 0.99 & $0.96-1.01$ & 0.549 \\
\hline R.E.N.A.L. $\geq 10$ & 2.12 & $1.09-4.12$ & 0.027 & 1.39 & $0.66-2.94$ & 0.380 \\
\hline $\mathrm{cT} 1$ & Referent & & & & & \\
\hline cT2 & 1.46 & $0.78-2.73$ & 0.236 & 1.35 & $0.50-3.65$ & 0.552 \\
\hline $\mathrm{cT} \geq 3$ & 2.73 & $1.38-5.37$ & 0.004 & 2.34 & $0.41-13.36$ & 0.337 \\
\hline \multicolumn{7}{|c|}{ OVERALL POST-OPERATIVE COMPLICATIONS } \\
\hline \multicolumn{7}{|l|}{ Type of surgery ${ }^{\dagger}$} \\
\hline $\mathrm{RN}$ & Referent & 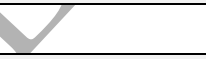 & & & & \\
\hline PN & 1.07 & $0.73-1.57$ & 0.716 & 1.67 & $0.89-3.15$ & 0.108 \\
\hline \multicolumn{7}{|l|}{ Technique $^{\ddagger}$} \\
\hline Open & Referent & & & & & \\
\hline Laparoscopic & 0.57 & $0.37-0.89$ & 0.013 & 0.73 & $0.42-1.26$ & 0.270 \\
\hline Robotic & 0.26 & $0.11-0.60$ & 0.002 & 0.38 & 0.14-1.00 & 0.052 \\
\hline \multicolumn{7}{|l|}{ Tumor features } \\
\hline Tumor size & 1.01 & $1.00-1.01$ & 0.004 & 1.01 & $0.99-1.03$ & 0.107 \\
\hline $\mathrm{cT} 1$ & Referent & & & & & \\
\hline cT2 & 1.78 & $1.17-2.71$ & 0.007 & 1.55 & $0.73-3.31$ & 0.247 \\
\hline $\mathrm{cT} \geq 3$ & 1.81 & $1.07-3.05$ & 0.009 & 1.03 & $0.26-4.11$ & 0.960 \\
\hline \multicolumn{7}{|c|}{ POST-OPERATIVE MAJOR COMPLICATIONS } \\
\hline \multicolumn{7}{|l|}{ Type of surgery $^{\dagger}$} \\
\hline $\mathrm{RN}$ & Referent & & & & & \\
\hline PN & 0.85 & $0.40-1.81$ & 0.683 & 2.05 & $0.80-5.21$ & 0.131 \\
\hline
\end{tabular}




\begin{tabular}{|r|c|c|c|c|c|c|}
\hline Open & Referent & \multicolumn{5}{|l|}{} \\
\hline Laparoscopic & 0.36 & $0.13-0.96$ & $\mathbf{0 . 0 4 2}$ & 0.42 & $0.15-1.14$ & $\mathbf{0 . 0 4}$ \\
\hline Robotic & 0.38 & $0.89-1.68$ & 0.206 & 0.44 & $0.09-2.14$ & 0.314 \\
\hline Tumor features \\
\hline Tumor size & 1.01 & $1.00-1.02$ & $\mathbf{0 . 0 0 7}$ & 1.02 & $0.99-1.04$ & 0.106 \\
\hline cT1 & Referent & & & & & \\
\hline cT2 & 3.25 & $1.31-8.06$ & $\mathbf{0 . 0 1 1}$ & 2.49 & $0.80-7.79$ & 0.115 \\
\hline cT $\geq 3$ & 3.88 & $1.40-10.73$ & $\mathbf{0 . 0 0 9}$ & 1.12 & $0.14-8.40$ & 0.910 \\
\hline $\begin{array}{l}\text { RN= Radical Nephrectomy; PN= Partial Nephrectomy; OR= Odds Ratio; Cl= Confidence } \\
\text { interval; }{ }^{\dagger} \text { Radical Nephrectomy vs Partial Nephrectomy; }{ }^{\ddagger} \text { Open vs Laparoscopic vs Robotic }\end{array}$ \\
\hline
\end{tabular}

Table 3. Univariate and multivariate analysis of the relationship between confounders and intraoperative, overall post-operative, and major post-operative complications.

\begin{tabular}{|c|c|c|c|c|c|c|}
\hline & \multicolumn{3}{|c|}{ Univariate analysis } & \multicolumn{3}{|c|}{ Multivariate analysis } \\
\hline & HR & $95 \% \mathrm{Cl}$ & $p$ value & HR & $95 \% \mathrm{Cl}$ & $p$ value \\
\hline $\begin{array}{c}\text { Charlson } \\
\geq 3\end{array}$ & 1.59 & $\begin{array}{l}1.08- \\
2.34\end{array}$ & 0.017 & & 0.94-2.09 & 0.093 \\
\hline $\mathrm{pT} \geq 3$ & 1.52 & $\begin{array}{l}0.97- \\
2.38\end{array}$ & 0.066 & 1.53 & $0.95-2.45$ & 0.074 \\
\hline $\mathbf{P N}^{\dagger}$ & 0.65 & $\begin{array}{l}0.44- \\
0.96\end{array}$ & 0.033 & 0.91 & $0.58-1.43$ & 0.705 \\
\hline $\begin{array}{l}\mathrm{HR}=\text { Hazar } \\
{ }^{\dagger} \text { Radical } \mathrm{N}\end{array}$ & $\begin{array}{l}0 ; \mathrm{Cl} \\
\text { ctom }\end{array}$ & $\begin{array}{l}\text { nfidence } \\
\text { Partial N }\end{array}$ & $\begin{array}{l}\text { erval; PN } \\
\text { irectomy }\end{array}$ & tial $\mathrm{N}$ & ectomy & \\
\hline
\end{tabular}

Table 4. Comparison between univariate and multivariate analysis of the relationship between type of the surgery and ACM 